\title{
Fostering appropriation through designing for multiple access points to a multidimensional understanding of physics
}

\author{
Olivia Levrini $\odot$ \\ Department of Physics and Astronomy, Alma Mater Studiorum-University of Bologna, \\ Bologna 40126, Italy \\ Mariana Levin $(0$ \\ Department of Mathematics, Western Michigan University, Kalamazoo, Michigan 49008-5248, USA \\ Paola Fantini \\ Liceo Scientifico A. Einstein, Rimini 47923, Italy
}

(Received 8 July 2019; accepted 7 February 2020; published 4 December 2020)

\begin{abstract}
[This paper is part of the Focused Collection on Curriculum Development: Theory into Design.] The overarching goal of this paper is to illustrate the interplay between theory, design principles, and curriculum (meant broadly, to include both written and enacted curriculum). This dialogue is illustrated in the context of the design and implementation of a particular curricular unit on thermodynamics intended for advanced secondary students in Italy. The approach to the discipline and design of learning materials that we take in this work challenges a conventional view of physics disciplinary content as hierarchically organized and instead promotes a multidimensional and thematically organized physics curriculum. In this paper, we emphasize not only the influence of theory on design, but also the reverse influence: how the analysis of specific classroom data from enactments of a designed curriculum can contribute to refining and building a local theory of how to learn and teach physics in a way that is inclusive and responsive to classroom diversity.
\end{abstract}

DOI: 10.1103/PhysRevPhysEducRes.16.020154

\section{INTRODUCTION}

In this paper we describe a three-phase dialogue between theory, curriculum design, and classroom implementations that progressively led us to lay the groundwork for building a local theory of how to learn and teach physics in a way that is inclusive and responsive to diversity. As diSessa and Cobb argue, local theories are usually explicitly developed through design-based research and do work in "generating, selecting, and validating design alternatives at the level at which they are consequential for learning" [1]. Local theory development often involves ontological innovations-the construction of theoretical constructs that empower researchers and, then, teachers to "see order, pattern, and regularity in the complex settings" where teaching and learning occur [2]. While the importance of theory in design-based classroom research is often emphasized in educational design work [3-5], the specific ways that

Published by the American Physical Society under the terms of the Creative Commons Attribution 4.0 International license. Further distribution of this work must maintain attribution to the author(s) and the published article's title, journal citation, and DOI. theory is shaped in response to curriculum implementation are less articulated within the constraints of typical empirical reports that are based on the design and implementation of innovative curricula. In particular, we contend that the complexities of iterative curriculum design deserve to be illustrated in detail, without defaulting to a linear model in which there is a one-way relationship from theory to curriculum design. For example, as designers, we claim the field needs to consider how theoretical influences of different grain sizes and scope can be progressively refined through iterative processes of design implementation. In our case we will be particularly interested in (i) underlying metascientific commitments related to the structure of the discipline of physics, (ii) principles for designing learning environments for inclusivity, and (iii) results and constructs from specific learning theories. We offer our case to the field as an illustration of how curriculum designers can be attentive to multiple design layers over multiple iterations.

We start with some context regarding our particular case. About fifteen years ago the Bologna Physics Education group began a program of work to address critical issue that Sjøberg pointed out as one of the main results of an UNESCO survey [6] on the attitudes of the young towards science and science education: 
"A key aspect in the lives of young is the search for meaning and relevance. They like areas where their voice is taken seriously, where their views count. Science and mathematics have an image of authority, at least as school subjects. Answers are either right or wrong. There is no place for arguments and personal views. [...] The lack of personal meaning and the image of eternal truth and correct answers put off more young people today than before" [7].

This result showed that the problem of students' disaffection was not simply related to the demanding nature of the discipline of physics, but with a perception of lack of sense and relevance. Thus, the issue was not "simply" to make physics easier and easier but actually to avoid those hyper-simplifications that, in cutting down the level of difficulties, remove the sense students feel in studying science. As Lévy-Leblond poetically says, simplification, if it is not taken under control, can become dangerous, a trivialization acting as the "new medusa": "More than the complexity of the original concepts of science, it is, on the contrary, their trivialization [...] that, as soon as the concepts reach nonspecialized public, exerts a real spell that petrifies them" [8].

Consistently, our overarching goals have been to design learning environments that allow all students to make sense of physics content and their own learning. That is, similar to the call from Duschl [9] and Roberts and Bybee [10], our goals for learning surpassed the acquisition of the specific content knowledge required to become future physics professionals. For the past 15 years, the physics education research group at University of Bologna has been working to design curricula for upper secondary students around the idea that restructuring physics content itself may be instrumental in both fostering deep understanding and reaching students with different intellectual interests, especially students who may not feel welcomed into the stereotypical physics "club." The designed materials have been tested and progressively refined across classroom implementations at different levels, including regular secondary school classes and in physics education courses for students pursuing a master's degree in physics. Thus far, the group has worked on advanced physics topics (thermodynamics, relativity, and quantum physics) that are part of the secondary school physics curriculum in Italy.

Previous studies have shown that students, in taking part in our learning environments, appeared to be personally involved in learning the material, and have come to talk about physics content using their own idiosyncratic ideas that helped them make sense of the material. Thus, instead of a "schoolish" language derived from borrowing expressions from the teacher or the textbooks, students in our classes have been shown to use personal ways to talk of the physics content. We called this phenomenon appropriation and in a previous study, we have operationalized it in terms of discourse markers that we argued characterized the discourse of students who added their own tastes and purposes to the content they were learning [11]. Operationalizing the construct of appropriation for science learning allowed us to go back to the curricula and to flesh out the features that could influence student's learning, as well as to unpack the instruction practices that allowed students to find their voices while grappling with the material [12].

In this paper, we present an analysis of the long process that led us from theoretical principles to ontological innovations (such as appropriation) and vice versa. To describe the interplay between theory and curriculum, we have organized the argument flow as follows.

In Sec. II, we present the first phase related to curriculum design. We then describe the three theoretical references that shaped our curriculum design: a metascientific perspective-the model of educational reconstruction [13] developed by Duit and colleagues, a perspective on the role of culture in learning and the principles for designing for inclusivity developed by Nasir and colleagues [14], and, lastly, a perspective on conceptual learning, coordination class theory, developed by diSessa and colleagues [15]. A point we wish to particularly underscore is that these three theoretical references are quite different in their scope and grain size and that this variation affects both the way the theory influences curriculum design and the way curriculum design and its implementation are able to speak back to each of the original theoretical references.

In Sec. III we provide an overview of the main results we have obtained in our published analysis of students' reactions to the curriculum implementation and we will illustrate the construct of appropriation that we operationalized in our first-level analysis of this data.

In Sec. IV we will show how operationalizing the construct of appropriation allowed us to speak back to the level of design criteria contributed to extending or elaborating our theoretical references. Specifically, we will show how the construct of appropriation led us to recognize Nasir et al.'s principles in students' discourse and provided concrete suggestions for building a diversity-responsive learning environment in physics (Sec. IVA). We then discuss how the construct of appropriation contributed to elaborating coordination class theory through the introduction of the concept of "personal concept projection" (Sec. IV B).

In the final section, we take stock of what has been accomplished thus far with respect to building a local theory of teaching for appropriation, outlining what next steps in the dialogue between design and theory building would be. We conclude by connecting our specific case with the discussion in the field around the dialogue between theory and design more generally. 


\section{MULTIPLE THEORETICAL PERSPECTIVES AND THEIR BROAD INFLUENCE ON THE DESIGN OF CURRICULAR MATERIALS}

Laying the groundwork for our design principles, we were influenced by multiple theoretical references of varying grain sizes. In this section, we describe these theoretical references, starting from the broadest influences -metascientific considerations concerning the nature of physics - and then working our way to more and more specific theoretical perspectives that inform our curriculum design work. For example, we begin by unpacking the question of "What image of science lies behind our design?" and describe how Duit et al.'s model of education reconstruction influenced our work by offering a view of science as plastic and reconstructible as opposed to fixed and hierarchical. We then turn to questions related to the learning of science at the level of access and equity: Why do we teach science and who should learn it? To engage at this level, we were guided by Nasir et al.'s principles for designing for inclusive learning environments. Having articulated our metaprinciples around the nature of science and who should be learning science, we then turn to the mechanisms behind how students learn scientific content. In this, we were guided by a theory of conceptual change, coordination class theory, that describes canonical learning processes and problems in learning a wide variety of scientific content. The relationship between these theoretical influences and our curriculum design principles (and, eventually, materials) are described in the following sections.

\section{A. Naming metascientific commitments-What image of science lies behind our design?}

In beginning to implement our goal of making sense of science content and their own learning processes, as described in the introduction, in curriculum designs, we were informed by the model of educational reconstruction (MER), a methodological framework that combines analytical and empirical educational research with the development of practical educational strategies (e.g., Refs. $[13,16]$. MER was developed in the mid 1990s on the basis of a continental European view of science education [17]. We adhere to MER in its epistemological commitment that physics is a discipline that, like every human construction, has its own "plasticity." That is, physics is rich and complex enough to allow its content to be analyzed, elaborated and restructured in many different ways according to many different educational goals. MER implies that, when science is analyzed, elaborated and restructured from an educational perspective, three different elements have to be combined: clarifications and analysis of science content, research on teaching and learning with emphasis on students' perspectives, and design of learning environments. The close interplay of these components is essential in the constructive orientation of the MER, according to which the content structure for basic instruction cannot be taken directly from the science content structure as it were a monolithic body of knowledge. Instead, the structure of the content in instruction has to be specially (re)constructed by paying attention to the specific educational goals of the design as well as to students' cognitive, aesthetic and affective perspectives [13].

Previously, MER had been employed by other researchers in developing teaching-learning sequences for several physics topics, including chaos theory [17] and nonlinear systems [18]. More recently, MER has been applied in developing a further model for science teacher education [19] and for the development of science exhibitions [20]. Prior to the application on thermodynamics, the physics education group of Bologna had used this model in the production of materials on relativity [21,22] and quantum physics [23]. In that work, the Bologna group incorporated in their reconstructions the use of historical papers of the developers of landmark physical theories, involving debates on foundational or epistemological issues of special relativity or quantum physics (e.g., the debates on the nature of space and time between Einstein, Minkowksi, and Poincaré; the debate about visualization between Heisenberg and Schrödinger; the debate of the meaning of complementarity and uncertainty between Einstein, Bohr, Heisenberg, and Schrödinger) [21,23].

From the implementation of those curricula with secondary school students, we had obtained confirmation that incorporating the history of science could offer a fruitful basis for implementing the plasticity of physics knowledge into educational materials and helping students create an authentic image of physics that stood in contrast to a stereotypical image of science in which there is no room for individuals to take personal stances. In our experiments, we found that historical debates had impressive potential illuminating the creative process in the development of scientific ideas and for communicating the sense of argumentation and comparison of different perspectives that is typical of science. Historical debates also provided a window for students to observe how many interpretations are possible and what interpretative choices are made when doing science [24].

\section{B. Naming theoretical commitments related to science learning processes}

Our curriculum design was further informed by theoretical frameworks belonging to more narrow levels of commitments related to fostering productive conditions for learning and learning processes. At this level, two different and complementary references played the most influential roles: a perspective on cultural diversity and inclusivity developed within the learning sciences by Nasir and colleagues [14] and the Knowledge in Pieces epistemological perspective, and coordination class theory in 
particular, proposed by Andrea A. diSessa [15]. We give a brief description of each of these perspectives in this section.

\section{Naming social and cultural commitments-Science, for whom and for what?}

As discussed in the introduction, many students are not interested in STEM because of their perceptions of these disciplines. In the case of physics, if the discipline is seen as an exclusive club of a certain kind of "physics person," then this can make the learning space very unwelcoming. Thus, important questions are "How can we make physics classrooms a more inclusive space? Can students who have a variety of different intellectual interests or cultural resources feel welcome in physics classroom spaces?" Within the learning sciences broadly, Nasir and colleagues discussed designing learning environments for inclusivity in a way that we found very resonant with our aims.

In their work, Nasir and her colleagues started from the premise that culture is integral to learning, where what they mean by culture is "the constellations of practices historically developed and dynamically shaped by communities in order to accomplish the purposes they value. Such practices are constituted by the tools they use, the social networks with which they are connected, the ways they organize joint activity, the discourse they use and value (i.e., specific ways of conceptualizing, representing, evaluating and engaging with the world)" [14]. From this perspective, learning involves acquiring and adapting diverse repertoires of cultural practices. In line with this definition, we can also consider science and mathematics to be cultures, as they have their own historically developed practices, tools, social networks, ways of organizing joint activity and valued discourse. Learning science and mathematics thus involves navigating among and between personal and disciplinary repertoires of tools, discourses, and means of organizing activity.

Across many empirical studies, Nasir et al. arrived at a set of principles for the design for learning environments that foster inclusiveness. These include (i) making a learning context "psychologically safe," i.e., attending to students' needs for a sense of belonging and identification; (ii) making visible the structure of the disciplinary domain; and (iii) providing students with a sense of possible learning trajectories. As described in Nasir et al.'s work, these principles can work at the level of orchestration of classroom discussion and didactical strategies, such as cooperative learning. In our case, these principles informed the process of restructuring of the content and teaching materials to make physics a subject matter where ideally all students could find their own positioning with respect to the discipline and nurture their own personal talent and interests. For us, Nasir et al.'s design principles acted as metaprinciples that we took as pillars of designing classroom spaces for inclusivity.

\section{Naming learning commitments-What does it mean to learn science?}

The second reference that influenced our designs at the level of specific commitments about learning is coordination class theory [15]. Coordination class theory (CCT) is situated within the knowledge-in-pieces epistemological perspective [25]. Coordination classes (described below) addresses the issue of what it means to "have a concept" and provides a model of expert conceptual understanding and its development. Coordination class theory is not intended to cover all cases of conceptual change as not all concepts are coordination classes. However, quantities such as force [5], expected value [26,27], velocity [28], proper time [29], and programming state [30] have been productively explored using the coordination class model. Over the last twenty years, a growing number of researchers have adopted the coordination class model to explain and further specify learning issues and processes and thus, we (as well as others in the literature) use "coordination class theory" to refer to the system of explanatory ideas that have emerged from this body of work. In particular, coordination class theory has the character of a humble, local theory [1] that is designed to be revised, improved, and extended, through ongoing attempts to apply the model and test its predictions against data.

Within the range of possible theories of learning, we were attracted by CCT because of its assumptions regarding knowledge as a complex system. Smith, diSessa, and Roschelle [31] and then later Scherr [32] argue that, in order to capture the complexity of learning processes, it is productive to keep the properties of a "pieces" model of student thinking in mind. That is, learning is more complex than adding new ideas or replacing one fully formed idea with another. Coherence of ideas is not denied, but it is also not assumed.

In CCT, well-formed concepts modeled as coordination classes are assumed to be complex, large and intricately organized systems, which effectively coordinate activation and use of many specific elements according to context. A concept is defined according to its function of "reading out" a characteristic class of information across the contexts in which one encounters it in the world. The particular knowledge used in specific applications of the concepts is called a concept projection. It is expected that students will develop multiple concept projections on their way to developing a coordination class. Thus, it is possible (and in fact, necessary) to form particular concept projections prior to developing a full coordination class. CCT posits two primary characteristic problems in interpreting the difficulties that students have in developing new coordination classes: (i) The problem of span: having adequate conceptual resources to operate a concept across the wide range of contexts in which it is applicable (i.e., having a sufficient range of functional concept projections) and (ii) The problem of alignment: being able to determine the same concept-characteristic information across diverse 
circumstances (i.e., coordinating concept projections across contexts).

Prior to the design of the thermodynamics unit, CCT was used by Levrini and diSessa to interpret a classroom episode where students showed difficulties to cope with the concept of proper time in special relativity but then they made progress in improving their understanding [29]. In that context, coordination class revealed itself to be very effective for interpreting students' difficulties in terms of lack of span or alignment but, even more interesting, the theory was able to explain why students progressively improved their understanding during a classroom discussion. In particular, CCT was able to flesh out how the processes of widening span and improving alignment, considered fundamental for conceptual change, were encouraged by the teaching strategy to expose students to the task of exploring, managing, and relating multiple classes of projections of the same concept (in that specific case, the concept of proper time) [29]. The lesson we learned from that previous experience was that exposing students to multiple definitions and multiple contexts is a productive and theory-motivated instructional technique since it has the potential to induce processes of conceptual changes that form the basis of the construction of wellformed coordination classes.

Building on these theoretical references we created a set of design principles that, we argue, foster both meaningful understanding of physics and inclusivity by creating multiple access points for developing a multidimensional understanding of physics. We describe the design principles we arrived at in the next section.

\section{From theory to design principles}

The design of the teaching materials on thermodynamics was carried out to achieve two complementary aims: (i) fostering deep conceptual understanding and (ii) creating a learning environment inclusive and rich enough to enable each student to navigate the conceptual terrain in a personally meaningful way.

Starting first from the level of commitments about the nature of knowing and learning, the coordination class model guided us in the explicit design choice to offer students multiple definitions of the same concept and offer them opportunities to think about concepts in multiple contexts. We elevated this choice to the rank of a design principle and we called it multiperspectiveness. Multiperspectiveness became the principle that flagged for us the goal of fostering conceptual change and, hence, deep understanding of the basic concepts. Multiperspectiveness then was enriched to mean something more than enlarging the contexts where the concepts could be operated. It indeed eventually also played a fundamental role in implementing Nasir et al.'s principles for inclusivity as they call "attending to students' needs for a sense of belonging and identification" and "providing students with a sense of possible learning trajectories" [14]. Indeed, when we contrasted the possible projections of a concept like proper time or temperature in different contexts or according to different definitions (for example, the operational definition of proper time or temperature vs the geometrical definition of proper time or the microscopic definition of temperature), we considered the projections not only for their mere conceptual content. We considered them also for the approach to the content they embody, that is for the epistemic forms of modeling, reasoning, arguing that they include and for the epistemological stances the express.

To emphasize this point we introduced a second principle: multidimensionality. Multidimensionality concerns the analysis and comparison of different perspectives across multiple levels: conceptual, experimental, and applied but also for their philosophical-epistemological peculiarities. As we will see in the next section for the case of thermodynamics, multidimensionality is introduced operationally through a plurality of activities, including the analysis of different texts and materials, like historicalepistemological essays. Multidimensionality was our means of implementing the plasticity of physics knowledge into educational materials (à la MER) and creating an image of physics where there is room for individuals to take personal stances. Specifically, it became a way to introduce in the classroom discourse different "voices," like the voice of Einstein to introduce the algebraic or operational approach in special relativity, contrasted with the voice of Minkowski presenting the geometrical approach. The voices become part of classroom discussions and served to enlarge the span of possible learning trajectories by offering at least two examples of them for each topic. For all these reasons, multidimensionality is the design principle of ours that refers to the goal of make physics learning inclusive by making the learning environment "psychologically safe" (attending to students' needs for a sense of belonging and identification) and by providing students with a sense that a plurality of learning trajectories are possible.

Lastly, we identified a final principle, longitudinality, in order to capture the sense making that we wanted to encourage for students across the different theories and topics they were learning. An example of theme is modeling and its specifications in different topics and domains [33]. Longitudinality is implemented by tutorials or in specific lessons where students' attention is focused on the "chapters" of the collective story the class is developing. Longitudinality, being explicitly focused on showing what science is and what makes it peculiar with respect other subject domains, has the main role to connect to the overarching goal, coming from Nasir et al., to make the epistemological structure of the discipline visible.

In Fig. 1 the three design principles we just described are summarized. In the next section we describe how they have 


\section{Design Principles}

Multi-perspectiveness

Students have the opportunity to operate the same concept across multiple definitions and contexts

\section{Multi-dimensionality}

Students have opportunities to analyze and compare the same content across multiple dimensions: conceptual, experimental, epistemological

\section{Longitudinality}

Students have opportunities to explicitly position current content they are studying with respect to previously learned content in terms of long-term scientific themes such as approaches to modeling and argumentation.

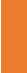

FIG. 1. Curricular design principles of the Bologna group, implemented across multiple units for advanced high school physics students.

been implemented in the design of our thermodynamics curriculum.

\section{The curriculum, that is, its structure and the implementation of the design principles}

In this section, we offer an overview of the curriculum unit on thermodynamics we designed according to the design principles we described in the previous section. We make particular note that the novelty of this design does not lie in the use of special teaching tools, special technologies or special lab activities. Rather, it consists in the structure of the discourse where the attention to the conceptual details is combined with the attention to build a coherent big picture, where complex argumentation is developed so as to flesh out a robust epistemic structure. Such a structure was needed in order to create a scaffolding for organizing the information that is present in the typical thermodynamics curricula and that are often only weakly connected among them and with the other chapters of physics that students learn.

In particular, the primary radical reconstruction consists not only of presenting the same content from two perspectives (the macroscopic and microscopic perspectives) but also, primarily, of emphasizing the epistemic relationship between them. In standard presentations of disciplinary structure, the micro- and macroperspectives are intended to cohere, with the microperspective possibly supplying a mechanistic explanation of the macroprinciples, or with both perspectives providing consistent insights into the same phenomena. By contrast, for multidimensionality reasons discussed below, we explicitly activated the epistemic dimension able to treat the micro- and macro-approaches as different epistemic approaches for interpreting a phenomenon and as different structural ways to organize knowledge. So, instead of focusing on helping students "translate" between the micro- and macroperspectives, as urged by many physics and chemistry education researchers (e.g., Ref. [34]), we focused on helping students see the epistemic and structural differences between the micro- and macroperspectives, and we invited students to adopt and adapt the approach that makes sense to them given their identities, philosophical orientations, etc. This explicit multidimensional comparative approach, though introduced as meeting criteria abstracted from Nasir and colleagues (see below), was also the one way in which the disciplinary content structure was truly reconstructed in the MER sense.

As for the details of the path, they have been informed by results on students' difficulties in learning thermodynamics from the physics education research literature. There is indeed a long research tradition in investigating the problems of understanding the concepts of temperature and heat [35-37], heat and work, their relationship and their character of being process variables [38-40]. Further relevant studies highlight students' difficulties in managing the variables involved in the thermodynamic description or explanation and, in particular, in relating the first principle and the ideal gas law [41-43]. For our design it was very important to start from well-known results that most of the learning problems students encounter can be interpreted either in terms of difficulties in considering more than two variables at a time or in terms of confusion between macroscopic and microscopic levels of description $[41,43,44]$. As far as the second law is concerned, studies that informed (or strengthened a posteriori) our design were those that pointed out students' difficulties in the following: (i) understanding the meaning of irreversibility in the second law [45]; (ii) managing the relationship between entropy, second law, and spontaneous physical processes; (iii) recognizing the relevance of the second law in solving problems about cyclic devices (heat engines and refrigerators) [46]; (iv) understanding basic probability concepts needed to comprehend the microscopic view of the second law [47]. The research results referred to above have been analyzed so as to point out the critical details that need to be emphasized and problematized in the unit. Additional materials on such critical details were produced and activities were organized to support students in grappling with the issues suggested by the research literature. For example, items based on the papers of Ref. [41] have been an object both of classroom activities and of the intermediate test on the first principle and the law of ideal gases.

As far as the overall structure of the teaching path is concerned, it was built according to the structure of 
thermodynamics as a theory. After an introduction about the primitive concept of equilibrium, the zeroth principle and the concept of temperature, the path was articulated in two parts about the first and the second principle, respectively. As anticipated, the main novelties are represented by how the three design principles were used to build the big structure of the teaching path and, specifically, by how we implemented multiperspectiveness, multidimensionality, and their mutual relationship.

Concretely, our approach to implementing the principle of multiperspectiveness was to articulate each part of the path in two subparts, one for the macroscopic and the other for the microscopic perspectives. So, in the first part of the path (about the first principle) the concepts of temperature, pressure, and internal energy included analyses first from a macroscopic approach and, then, using the kinetic theory of ideal gas. Then, in the second part of the path (about the second principle), entropy, heat, and work were first addressed from a macroscopic perspective and, then, using the Maxwell-Boltzmann statistical approach.

This structural organization reflects also a basic choice that is implied by our particular way to implement multiperspectiveness: the micro- and macro-approach had to emerge as based on robust and consistent forms of knowledge organization. This would have made it possible to switch on the epistemic dimension, that is one-if not the main-dimension in our sense of multidimensionality. Indeed, as already highlighted, this choice aimed to treat the two approaches as two different epistemic ways to interpret a phenomenon. In order to implement this choice that links multi-perspectiveness and multidimensionality, we adopted an explicit comparative approach: each perspective was treated separately so as to highlight its inner consistency, and, then, the two were compared, so as to stress their peculiarities. In the following we describe the main challenges we addressed to keep and highlight the coherence within each approach and its epistemic features.

As for the macroscopic parts of the conceptual path, the reasoning was developed to address the following question: "how does the game of modeling (systems and processes) change from mechanics to thermodynamics? The main challenge we had to face concerned searching for a way to address three kinds of apparent paradoxes of the modeling game of the macroscopic approach: familiarity and abstractness; processes and steady states; reversibility and irreversibility. We discuss each in turn.

(a) Familiarity and abstractness. - In spite of the feeling of familiarity suggested by words like temperature, heat, and energy, access to their scientific meanings requires the construction of deeply abstract reasoning. For example, the definition of temperature in a consistent macroscopic way, avoiding both tautologies (temperature is what is measured by a thermometer and a thermometer is what measures temperature), and any reference to its microscopic interpretation, requires a long process where the inner consistency of argumentation must be made explicit. The argumentation we followed started by recognizing both the meaning and the status of principle to the zeroth principle. The zeroth principle contains the assumptions that we can split the universe in different systems and that most of the systems (all but the systems, like the human body, that we will call thermostats) have the natural tendency to reach an equilibrium state when they interact with another system or with the rest of the universe (the environment). Thus, equilibrium is assumed to be a primitive concept and the state of equilibrium is supposed to be empirically recognized. Indeed, there are variables of a system that can be influenced by the environment but that, after some time, do not change any more (thermometric properties). They are, for example, the length of a column of liquid, e.g., mercury and alcohol, electrical resistance, emf of a thermocouple, to name a few. The expression of the zeroth principle as a transitive property provides the relation of "being in equilibrium" the mathematical structure of an equivalence relation [48]. This means that the universe can be organized in equivalence classes, each of them characterized by a measurable value of a chosen thermometric property. The physical property that characterizes all the systems that are in equilibrium and that can be measured by a thermometric property is called temperature.

This is a long argument that implies a sophisticated distinction between "assumptions," "principles," and "models of objects/systems." Such distinctions draw an argumentation scaffolding which provides a relevant contribution for reaching two aims: (i) helping students to understand the physical concept of temperature, by linking it to the zeroth principle, and (ii) enabling students to face explicitly why that type of abstractness is needed to account for phenomena whose perception is commonly described by familiar words. As for the concept of heat and energy, we particularly emphasized the distinction between process and state variables and the brief history of the word heat was shared with the student, by stressing that the conception of heat moved from being considered a substance ("caloric") to a process ("a way to transfer energy by exploiting the difference of temperature between two systems and their "natural tendency to reach an equilibrium state") [49,50]

(b) Processes and steady states.-In spite of the name thermo-"dynamics," the dynamical explanation of the system's evolution disappears behind the strange choice of modeling processes as sequences of equilibrium states in a $p V$ diagram, that is, a sequence of states where the macroscopic quantities of $T, P$, and $V$ are known and measurable. Traces of the dynamical processes are only recognizable in the distinction between process and state variables. The concept of 
process variable was stressed as a fundamental criterion to compare heat $(Q)$ and work $(W)$ and to point out their property to be "equivalent" ways to change the energetic state of a system. This equivalence has been analyzed by reflecting on the Joule experiment where the empirical and the conventional aspects have been pointed out. This form of "equivalence" was reanalyzed from the "entropic" lens, thanks to which heat and work show their deep difference.

Another type of reflection that was carried out to make the dynamical model of thermodynamics explicit, concerns the model of the ideal, quasistatic transformations used in the macroscopic approach to thermodynamics. This model can be shown to implement a mechanistic view of interaction in the sense that the system is assumed to have, at any time, welldefined macroscopic properties whose change is interpreted in terms of "interactions" with an external causal agent that controls, deterministically and step by step, the whole process.

(c) Reversibility and irreversibility.-Even though the second principle aims to determine a quantity (entropy) for describing and "quantifying" the irreversible change of phenomena, such a quantity is defined on reversible transformations. A system that evolves in an irreversible way forgets initial conditions and it does not return spontaneously to its initial state; a system that evolves in a reversible way remembers the initial conditions and it can return and go on. In order to address this seeming paradox, an articulated argument was carried out so as to guide the students to recognize the various meanings of entropy that emerge from the game between models and reality. The argument we used started from the observation that, in daily life, we experience the irreversibility of real processes and this evidence is not yet explained by the zeroth and first principles of the thermodynamics. Then, we focused on emblematic types of spontaneous and irreversible transformations: free expansion of a gas, heat transfer from a body at a higher temperature to a body at lower temperature, dissipation of mechanical-electricenergy by friction. At this point, we announced our statement for the second law that "elevates at the rank of principle" a "fact of nature," that is, the irreversibility of spontaneous evolution of natural processes: "If a system spontaneously evolves from an equilibrium state to another, such transformation is irreversible: there is no transformation that can produce the only result of bringing the system back to its initial conditions." The two statements of Clausius and Kelvin can be seen as special cases of this more general formulation, when we focus on specific cases of irreversible processes: heat transfer from a body at a higher temperature to a body at lower temperature (Clausius's statement), dissipation of mechanicalelectric - energy by friction (Kelvin's statement) [50].
With the general statement of the second law, the students are now ready to explore the meaning of irreversibility, by moving from reality to idealization and by analyzing what happens if we consider ideal quasistatic transformations of perfect gases where all the sources of irreversibility are removed: inner sources of friction, temperature gradients that would induce heat transfer, the conditions for a free expansion [51]. If we remove all these sources of irreversibility, we have reversible transformations that can occur in both directions and we can wonder: what can such reversible transformations say to us about the irreversibility of natural phenomena?

If we apply these ideal reversible transformations to ideal cycles, that is, to thermal engines, like the Carnot engine, it becomes possible to point out an "intrinsic" (not removable) asymmetry between heat and work: the engine's efficiency is less than 1, even in absence of irreversible processes. This implies that heat has something "special" with respect to work and, by analyzing what happens in an ideal Carnot's cycle, we can infer that when energy is transferred via heat in an ideal transformation also another quantity, besides energy, is transferred. This is entropy, whose formal expression is

$$
\Delta S=\int \frac{\delta Q}{T} .
$$

Its properties as a state, extensive, conservative (for an ideal transformation) variable allow it to be formally and imaginatively treated as a "flow of something" that can be exchanged from one system to another when they interact by changing energy via heat. In this very delicate point, the students were progressively guided to attach a consistent meaning to the expression "a flow of something" and, thus, to move from the concept of heat, that is the process variable that characterize the mechanism of transfer, to a new state quantity that must hence have properties more similar to energy. In such a way, the students were gradually guided to consider how this heat-related entity can be defined as a state function. This new state variable, entropy, when referred to ideal transformations is able to differentiate between work and heat: in ideal transformations interaction via work transfers only energy whereas interaction via heat transfers both energy and entropy. Thanks to this new conceptual tool, it is now possible to move back from idealization to reality and, to "quantify the entity of irreversible change" (the etymological meaning of entropy) in a real transformation occurring within an isolated system (at the limit, the universe) and by exploiting the property of entropy to be a state variable.

To end the macroscopic approach, a reflection on the concept of heat was carried out: while the first principle of 
thermodynamics highlights the energetic face of heat and stresses in equivalence with work $(Q=\Delta U+L)$, the second principle highlights its entropic face and its inner difference from work $(Q=T \Delta S)$ [52].

As for the microscopic parts of the conceptual path, the main challenge we had to face concerned the search for a way to stress the classical view of Newtonian mechanics that underlies the kinetic theory of gases and the revolutionary contribution provided by Maxwell and Boltzmann when they "invented" statistical mechanics and introduced in physics concepts likes a priori probabilities, complexions, micro- and macrostates. The Italian secondary curriculum foresees that, in the same period, students learn the theory of probability in mathematics, so explicit connections between physics and mathematics can support the students in recognizing the difference between a probabilistic approach based on a frequentist definition of probability and an approach based on the concept of a priori probability. A careful discussion of the thought experiment of Maxwell's demon and the status of the second law concluded the path [53].

In order to operationally introduce multidimensionality into the curriculum, we took care to use consistently and explicitly the different semantic fields that characterize the discourse: the empirical, engineering, mathematical, logical, historical, epistemological (mechanistic or phenomenological), social-economical (for the applications), poetical (words like entropy or arrow of time are deeply evocative) [54]. We stressed the peculiar genesis of thermodynamics that crossed different traditions and did not follow a linear path $[51,55]$. These peculiarities are mirrored both in the principles enumeration and in the stratification of the words and of the languages that can be found in every textbook chapter.

Moreover, explicit activities intended to activate multidimensionality were implemented. A questionnaire was designed to lead the students to reflect, first individually, then collectively, about the epistemological differences between the macroscopic and the microscopic approach. The questionnaire was given to students at the beginning of the unit and included extended texts of Einstein, Poincaré, and Drago concerning the meaning of a physical theory. In particular, it contained Einstein's popular text about the distinction between theories of principles (including special relativity and macroscopic thermodynamics) and constructive theories (exemplified by Newtonian mechanics and the microscopic kinetic theory of gases [56]). In order to orient students to the analysis of the texts, the questionnaire was organized into two parts:

1. An author-by-author analysis (e.g., What terms or expressions are, in your opinion, crucial for characterizing the kinds of theories described by authors $1,2,3$ ? Are there terms or expressions they used that were unclear or ambiguous to you?)
2. Comparative analysis (e.g., Do you see common aspects in the texts of the three authors? If so, how would you describe them? Do you see significant differences between the positions of the authors? If so, how would you describe them?)

The students were asked to answer the questions as homework. This individual activity was the basis for a collective discussion, carried out a few days later, in which students were encouraged to share and confront their reflections with the classmates, to develop their arguments, and to contribute to the construction of a collective epistemological awareness. A similar discussion was also carried out at the end of the unit.

The activities of discussing and comparing the two types of theories allowed the students to develop a vocabulary and arguments for reflecting on the limits of the validity of a theory or model and on the connections between reality, formalism, intuition, and argumentation as well as for positioning thermodynamics and its process of modeling with respect to other theories they had already studied. Special attention was indeed paid to compare thermodynamics with classical mechanics and special relativity (that the students had already studied). The comparison was carried out both as for the implied models of objects or systems and processes or transformations and for the overall structure of the theory. In this sense, the distinction between theories of principles and constructive theories was useful also to implement our third design principle, longitudinality. Further details on the thermodynamics teaching-learning path can be found in the article by Levrini, Fantini, Pecori, and Tasquier [57].

\section{AN EMERGENT PHENOMENON IN THE CLASSROOM IMPLEMENTATION: PERSONAL AND AESTHETIC ENGAGEMENT}

Having described the materials and the design criteria and theoretical considerations that went into implementing them, we now shift our focus to the other direction of the dialogue we set out to explore: how our design spoke back to the theoretical references. The materials have been implemented in several classes with different teachers. In the paper we refer to an implementation that we analyzed in great depth in previous papers and that we recap here to discuss the relationship between learning theories and curricula. This particular implementation took place in a public scientific liceo (high school), attended by students in the neighborhood.

Based on the research literature and results from prior implementations of curricula designed with similar principles, we had reason to expect that the learning environment we created would be support students in engaging with the conceptual content of the unit in a way that respected the complexity and integrity of the disciplinary content and that each student could be felt welcome in the "physics club." What emerged as surprising to us, however, 
was that during the activities, students progressively showed a very special and genuine way of feeling involved in and speaking of thermodynamics. In order to capture what we observed and perceived, a group of eight students (out of twenty) was selected as representative of the class and individual interviews were carried out at the end of the unit. The students were selected to represent different gender, attitude toward physics, level of performance, type of engagement during the activities. Out of the eight, only one student showed a very typical school attitude, while a second one appeared to be on her way to finding a personal positioning. In the interviews, all the other six students used very personal ways to talk about the specific concepts and showed an impressive capability to reflect, at a metacognitive and epistemological level, on their learning experience.

Consider, for example, two students from this group, Matteo and Michele. One question of the interview concerned the concept of temperature. As can be seen in the vignettes, they both described the concept by using correct ideas, yet their ways of discussing temperature had a very different, personally inflected, character. Matteo, in talking about the concept, made the choice to talk about temperature by comparing two formal relations in which it appears: the law of calorimetry and the law of the ideal gases.

\section{Matteo: [I think that] $Q=m c \Delta T$ is becoming}

$[\ldots] . .$. there is a change [because of $\Delta T]$ that means everything is not stable and everything is not being, there is something that changes.

[...]

Matteo: the first relation $[P V=n R T]$ is being because [...] [there is] absolute temperature T, that doesn't change. There is not $\Delta$ [difference in temperature], there is not the change...

This choice is not by chance or incidental. It is instead consistent with the epistemological stance that Matteo systematically showed during the activities and with his strong interest in philosophical speculations, much more than in mathematical formula:

Matteo: I believe that [...] it is fundamental to build a basis and to speculate on how theories are found, how concepts are elaborated. These concepts will certainly last longer than formulas. [...]

Both during the activities and the end of the thermodynamics unit, in the interview, he repeatedly claimed that thermodynamics was interesting for him because he could recognize, in that area, how physics can conceptualize and deal with the philosophical notions of "being" and "becoming." Thus, when discussing the concept of temperature, Matteo focused on the distinction between the temperature gradient $(\Delta T)$ and temperature $(T)$ because he could recognize, in this connection, the philosophical notions of becoming (change) and being (state). Matteo saw in the law of calorimetry $(Q=m c \Delta T)$ an expression of becoming "there is a change [because of $\Delta T$ ] that means everything is not stable and everything is not being, there is something that changes." In contrast, in thinking about the ideal gas law $(P V=n R T)$, he instead saw an expression of being: "[There is] absolute temperature $T$, that doesn't change. There is not $\Delta$ [difference in temperature], there is not the change..." When asked about what he liked most within the study of thermodynamics, he mentioned the arrow of time in the discussion of entropy. Matteo's idea expressed an epistemological positioning with respect to physics seen mainly as a discipline oriented to fundamental questions about knowledge, such as "What is time?" and "What is being?" In the approach to thermodynamics they experienced, he could enjoy and feel closer to a discipline that was not only "made of formulas" but "made of reasons, of [arguments that show] how one arrives to these formulas."

With respect to his personal interest, Matteo found more stimuli within the macroscopic approach since he could see there more answers to his philosophical questions. Matteo was a not a student who easily resonated with physics and its languages and he never became acquainted with mechanistic language. However, more than the choice between one approach or the other, he appeared to feel comfortable because of the epistemological dimension that was switched on during the module. This dimension allowed him to reinterpret concepts in a personal way and position himself with respect to the discipline and the class on the basis of his passion for philosophy. In contrast, when another student, Michele, was asked, during the end of unit interview, to talk about temperature, he said,

Michele: We have seen that, in Carnot's cycle, the temperatures influence the efficiency, the process, the cycle.

Interviewer: In what sense? Can you explain better? Michele: Different temperatures are necessary..., only with different bodies with different temperatures we can have a cycle and work; different temperatures induce a heat exchange-we can call it so-and the heat exchange induces a work; heat is turned into work.

In the excerpt, Michele focuses his attention on the temperature gradient because this is what makes engines work. As he explains, "Different temperatures are necessary ... only with different bodies with different temperatures can we have a cycle and work; different temperatures induce a heat exchange-as we call it-and the heat exchange induces work; heat is turned into work." Also in this case, the choice of Michele is not incidental, but consistent with what he repeatedly said throughout the thermodynamics unit, that is his interest in engines, objects, and how the world works: "I like physics because it 
explains how reality works, so to say, I'm very curious about how objects work and natural events." His discourse on temperature displays his epistemological positioning within physics according to which it is seen mainly as a discipline oriented to solving concrete problems. In class, Michele came to develop a social position in the class as a student who ensured that the collective discussion connected with the real world. Because of his interest in engines and mechanistic reasoning, Michele resonated in a genuine way, with the kinetic theory of gases and the focus on the thermal engines in the second law.

Notably, both Michele and Matteo discussed the concept of temperature in a way that was sound with respect to the discipline, yet not a repetition of a textbook or teacher definition of the concept. Instead, they each used their signature idea to focus attention on different pieces of knowledge related to temperature. This process of infusing a disciplinary word with personal tastes and intentions is at the heart of what the construct of appropriation captures.

Like Matteo and Michele, all the other students except one of the selected group could search for their own way to enter thermodynamics and make personal sense of it. We recognized this phenomenon as a case of what Bakhtin calls appropriation, referring to the process through which individuals infuse personal meanings into words or ideas borrowed from others [58,59]. Informed by this idea of appropriation, we used a bottomup process of operationalizing this construct in terms of five discourse markers that we felt captured the sense of students' specialized and personal discourse in the class. More specifically, we analyzed students' ways of talking about the content in the unit (such as the concept of temperature) in the end of unit interview, triangulated also with data from classroom observations throughout the unit to see if their discourse included the following five markers:

1. an expression of personal signature idea(s)

2. disciplinary-grounded discourse

3. thick discourse that involves the metacognitive dimension (what learning physics means for me) and the epistemological one (what epistemic aspects of physics make sense to me)

4. non-incidental use of the signature idea in the sense that their signature idea is used consistently throughout classroom activities, and

5. discourse that is a carrier of social relationships in the sense that the way they spoke about the content of the unit positioned the student within the classroom community [11].

If the discourse showed these features, we concluded that students appeared to have appropriated the specific concept. Operationally, we could claim that the discourse appeared as an expression of personal signature ideas when it was developed around a set of words or expressions repeated several times and linked together so as to express an authentic, idiosyncratic idea with respect to physics (thermodynamics). This idea was recognizable as authentic and idiosyncratic when it varied from student to student, and the linguistic choices and the tone showed indicated that the idea was not "borrowed" from an external authority. In the case of Matteo the idiosyncratic idea was the "philosophical distinction between being and becoming" that he used to navigate across the thermodynamic materials as a lens for personal sense making. For Michele the idiosyncratic idea was that physics gains its interests since it explains "how things work." When we say that the discourse of the students who appropriated physical concepts is both thick and grounded in the discipline we mean that the idiosyncratic idea is an expression of an epistemological view that consciously makes personal sense to them (thick in the sense that involves both an epistemological and metacognitive dimension) but is used by the students as a tool to understand the physical contents (grounded in the theory). The idea is indeed used to select pieces of disciplinary knowledge and coordinate them in a way meaningful from a physical point of view, namely, by respecting the rules and the constraints of the game of physics. This is a crucial aspect that we discovered in students' discourse that speaks back to the theory of coordination classes and that we elaborate in Sec. IV B. The marker of nonincidentality implies that the idiosyncratic idea can be traced back to the student's reactions in different classroom activities and, hence, it can be recognized within a personal story that extends beyond the duration of a single episode (interview). Finally, the last marker stresses that the idiosyncratic idea positions the student within the class community (the "engineer," the "philosopher," the "mediator") and, vice versa, the development of the idiosyncratic idea is inseparable from the classroom dynamics, the distribution of accountability, and the specific relationships that have been established in a class.

In our previous paper [11], we described in detail the methodological process that led us to identify the markers, operationalize the construct of appropriation, and thus turn it into a theoretical construct. The process was inspired by grounded theory and by the goal to pave the way to a "local theory" of appropriation able to explain when, why and how appropriation can be fostered and recognized in teaching. In the next section, we show how the operational definition of appropriation we bootstrapped from the data analysis of classroom implementations speaks back to our theoretical references. We will discuss how (a) the appropriation markers can be used as operational ways to recognize, in students' words, how Nasir et al.'s principles became part of students' ways of navigating across the physics materials (Sec. IVA); (b) the appropriation construct can be used to enrich and extend CCT by introducing the notion of "personal concept projection" (Sec. IV B). 


\section{FROM APPROPRIATION BACK TO THE INITIAL THEORIES THAT INFLUENCED OUR DESIGNED CURRICULUM}

\section{A. Appropriation in dialogue with Nasir et al.'s design principles for inclusion}

The phenomenon of appropriation per se shows that students found ways to develop personal relationships with the content they were learning and, hence, it was a strong indication that the learning environment was, using the words of Nasir and colleagues, a "psychologically safe" and inclusive space that fostered disciplinary learning of content (our two original design aims). However, the markers of appropriation that we operationalized can be used to better specify the way the perspectives that informed our initial design could be brought to life in our context and become visible in students' discourse.

In particular, the appropriation marker of a clear personal "signature" idea used to organize thinking about disciplinary content provides a check that the principle of Nasir et al. of belonging and identification was implemented in the class. Two remarks are of special importance for our overall approach. First, the marker shows that the materials $d i d$ work to implement the principle. We acted mainly at the level of content organization and while aspects of the implementation played a role (see the discussion for more detail on our subsequent study of the role of the teacher), we argue that the special shape we gave to physics through the organization of the materials made it inclusive. Second, the marker of a signature idea provides an operational way to recognize the specific sense of identification and belonging that they students felt and experienced. Learning of and in a science discipline can in fact become a way for students to develop their personal aesthetic, personal engagement and, hence, to form their identities. This result definitely runs counter to the trends and widespread practices according to which science, unlike sports or humanities, does not contribute to the formation of individual identities [60,61].

The principle of "making the structure of the discipline visible" is evident through the markers of "thick" and "nonincidental" discourse that are characterized both by their attention to epistemological dimension of the content and by the search for conceptual and epistemological coherence throughout different contexts and different topics. Finally, the principle of showing multiple possible learning trajectories is visible through the discourse evidence of the marker of social relationships and position within the classroom community. Students' awareness that their engagement with concepts mirrors the kind of debate the scientists have is evidence of their awareness of multiple possible learning trajectories. That is, that these different pathways to understanding are part of the process of doing science.

\section{B. How appropriation contributes to elaborating coordination class theory}

A different and perhaps even more substantial dialogue occurred between the classroom data and the specific theory of learning that influenced the design principle of multiperspectiveness, coordination class theory [15]. In Ref. [61], we analyzed again how students explained, at the end of the classroom implementation, the concept for temperature. There, we discovered that students generated a special kind of concept projection that was assembled around students' idiosyncratic "signature" ideas. Recall that in CCT, a concept projection is the part of a full coordination class that is activated in a particular explanation form [62]. Students do not need to have a full coordination class in order to construct concept projections in specific contexts. In fact, as we discuss in Sec. II B 2, one of the hallmarks of a coordination class in development is not having the full span and alignment of an expert understanding of how to determine a quantity. The special kind of concept projection that students generated allows us to provide an answer to a theoretical question at the heart of learning processes and personal sense making: where and how, in students' processes of constructing meaning for the concept of temperature, did they infuse personal meanings?

To illustrate the point, we draw again upon the excerpts from interviews with Michele and Matteo that we reported in Sec. III. From the excerpts, we observe that, in thinking about the concept of temperature, both Michele and Matteo engage in two related processes of selective attention: (i) selection of a context in which to operate the concept and (ii) choice of focus of attention (that is, aspects of the concept and related pieces of knowledge relevant to the concept in that context). Michele's explanation is tightly connected to his signature idea (his interest in engines, reality, and "how things work."). With Michele, the Carnot cycle is the context he chooses ("We have seen that, in Carnot's cycle, the temperatures influence the efficiency, the process, the cycle ..."). In this context, he focuses on the difference in temperature, because, he explains, the difference in temperature is what makes an engine work ("Different temperatures are necessary. Only with different bodies with different temperatures can we have a cycle and work; different temperatures induce a heat exchange-we can call it so-and the heat exchange induces work; heat is turned into work."). The choice of the context leads him to focus his attention on a special piece of knowledge regarding temperature "the temperature gradient" because "only with different bodies with different temperatures can we have a cycle and work cycle." In contrast, Matteo selects a completely different context for projecting the concept of temperature: the distinction between two relations that include temperature (i.e., the law of calorimetry and the ideal gas law). Still, the choice is consistent with his idiosyncratic idea represented by the philosophical distinction between becoming and being. The choice of the 
contexts leads Matteo to focus his attention on a special piece of knowledge regarding temperature: its being a state variable whose difference creates a process, a change. The distinction between change (process) and lack of change (a state) is represented by the presence and the lack of " $\Delta$." The presence or lack of $\Delta$ become the two foci of attention where he could make his projection of the concept of temperature. It is where he could infuse his personal meaning, inspired by his idiosyncratic idea.

Coming back to the kind of concept projection they generated, we can argue that they each, in their own ways, formed a personal concept projection by populating a disciplinary word with their own personal intentions and tastes. It is in this action of selecting contexts and pieces of disciplinary knowledge and coordinating them that we see how the process of grounding the discourse in physics becomes a locus of personal choice.

From a methodological point of view, the marker of being grounded in the discipline becomes a way to show, on one hand, the extent to which CCT is effective for interpreting the conceptual content of students' discourse and, on the other, how appropriation speaks back to CCT coordination class theory by suggesting a way to extend it. The notion of personal concept projections, when used to enrich CCT, reveals a way that disciplinary learning and identity formation can be intimately intertwined.

\section{DISCUSSION AND CONCLUSIONS}

This paper illustrates a multilayered process of both theory-inspired curriculum design and how analysis of curricular implementations can speak back to and develop theories of learning. In articulating this process, our aim was to exemplify one of the primary purposes of engaging in design-based research - the process of developing local or "humble" theories of learning [1]. In doing so, the importance of disambiguating the role of various theoretical influences, of multiple grain sizes and foci, became especially relevant. While our work contributes, at some level, to each of the theoretical references that framed our curriculum design process, the scale of the theories and their level of specificity, influenced the dialogue our designed curriculum and implementation had with each theoretical reference.

For example, at the broadest scale, the model of educational reconstruction provided for us a way to view the nature of physics as flexible and reconstructible as opposed to rigid and strictly hierarchical. That said, the particular contribution of our work to the dialogue with this perspective was our approach of including historical debates as a means of restructuring disciplinary content. At the next most narrow (yet still quite broad) scale, the principles for designing inclusive learning environments of Nasir et al. were extracted from learning in disciplines far from advanced secondary school physics (e.g., in the case of students learning basketball), and thus the particularities of implementing the principles in our context required substantial transformation (e.g., making the structure of physics explicit involves different design work than making the structure of basketball explicit). Lastly, coordination class theory, itself a humble theory of concept development, was a site for theoretical elaboration in our context because we were able to recognize in students' processes of reasoning also the process of making a concept one's own (via forming in-the-moment personal concept projections). This illustrates a link between disciplinary learning and identity development that had not been noticed for researchers interested in either concept learning or in identity development [63].

In addition to the dialogue between theory and the data coming from the learning experiences we designed, we wish to also remark on the mediating role that curriculum design principles played.

That is, while in some way, our design principles (multidimensionality, multiperspectiveness, and longitudinality) describe our approach to implementing the principles of MER, Nasir et al., and diSessa, the design principles themselves are not at the level of defining a local theory of learning or teaching. Thus, it is natural that in both looking at teaching and learning we would need to define new constructs and foci in order to operationalize the local theory of how, when, and why productive learning in our contexts occurs.

We have made some progress in further elaborating a local theory of appropriation, especially in light of the profound role of the teacher in how, exactly, the materials were brought to life in the classroom. Since our initial analyses of student appropriation [11], we have followed up our analysis with a secondary analytic focus on the way the teacher orchestrated discussions in a class in which appropriation by a majority of students occurred. For this next layer of analysis, we started from discussions with the teacher, who was a long-time collaborator on the curriculum design efforts of this and other units, about aspects of her practice that she felt were consequential for promoting deep engagement with the disciplinary content of the unit. Eventually, our analysis of classroom discourse and participant structures revealed that underlying the teachers' description of her aims and actions was a complex epistemological scaffolding that was articulated across four moments of a pivotal discussion in the unit (the discussion of the epistemological questionnaires mentioned in Sec. II). Each of these phases of the discussion had a different function, including involving students in the construction of a collective disciplinary narrative, introducing an epistemological dimension to the discussion by encouraging explicit reflection on comparing the different approaches the students had studied, then encouraging students to test out their criteria for comparing approaches, and finally, encouraging students to position themselves personally with respect to the multiple perspectives discussed and be 
prepared to defend their position. In Levrini et al. [63] and in Kapon, Laherto, and Levrini [64] we argued that these functions provided the scaffolding for physics to be a context for both disciplinary learning and students' search for personal relevance and meaning.

The case study of design and theory building examined here raises the usual issues of generalizability of results across contexts and how to expand the scope of a promising learning or teaching experiences. As is the case with all design-based research and local theory building, the case we have unpacked in detail is particular: it takes place in a specific school, with specific teacher, with designed materials, and in a secondary school context. From this one case, it is not possible to determine how the design would change if any of the above parameters changed. We will, however, note that we have observed cases of appropriation with other classes of the same teacher or of different teachers with similar students, studying other advanced topics, such as proper time $[18,22]$. Our ongoing work is aimed at understanding better the conditions under which appropriation occurs. This involves broadening to new content, new teaching contexts, and also new teachers.

In closing, we remark on the larger aims of our work. Our approach to design and instruction challenges a conventional organization of physics as hierarchically organized and instead promotes a multidimensional and thematically organized physics curriculum. This aspect brings to the fore several tensions and issues that often remain below the surface [64]. The most demanding one concerns the image of science: while inclusivity is a goal of STEM education professionals, progress towards this goal disrupts a normative and widely accepted system of privilege within the discipline itself by questioning who is good at science and math and who should have access. We hope our reflection on the interplay between theory and design can provide tools for other researchers and designers interested in nurturing students' personal and idiosyncratic ways of learning physics.

\section{ACKNOWLEDGMENTS}

This paper represents an a posteriori reflection of a long and iterative process of design and implementation that has involved, for many years, the whole research group in Physics Education of the Department of Physics and Astronomy of the University of Bologna. Among them, an important contribution has been provided by Giulia Tasquier, who was fundamentally involved in processes of data collection and analysis and in bootstrapping the construct of appropriation; we are deeply grateful to her. This publication is supported by research funds of the group in Physics Education of the Department of Physics and Astronomy, Alma Mater Studiorum, University of Bologna.
[1] A. A. diSessa and P. Cobb, Ontological innovation and the role of theory in design experiments, J. Learn. Sci. 13, 77 (2004).

[2] A. A. diSessa and P. Cobb, Ontological innovation and the role of theory in design experiments, J. Learn. Sci. 13, 84 (2004).

[3] A. L. Brown, Design experiments: Theoretical and methodological challenges in creating complex interventions in classroom settings, J. Learn. Sci. 2, 141 (1992).

[4] P. Cobb, J. Confrey, A. A. diSessa, R. Lehrer, and L. Schauble, Design experiments in educational research, Educ. Res. 32, 9 (2003).

[5] A. Bakker and D. Van Eerde, An introduction to designbased research with an example from statistics education, in Approaches to Qualitative Research in Mathematics Education (Springer, Dordrecht, 2015), pp. 429-466.

[6] S. Sjøberg, Science and technology education: A high priority political concern in europe, Science Education Research in the Knowledge-Based Society, edited by D. Psillos, P. Kariotoglou, V. Tselfes, E. Hatzikraniotis, G. Fassoulopoulos, and M. Kallery (Springer, Dordrecht, 2002), https://doi.org/10.1007/978-94-017-0165-5_23.

[7] S. Sjøberg, "Why don't they love us any more?" Science and technology education: A European high priority political concern!, in Proceedings of the Third International E.S.E.R.A. Conference, Thessaloniki, Greece (2001), pp. 19-20.

[8] J-M. Lévy-Leblond, La Vitesse de l'Ombre: Aux Limites de la Science (Seuil Paris, 2006).

[9] R. Duschl, Science education in three-part harmony: Balancing conceptual, epistemic, and social learning goals, Rev. Res. Educ. 32, 268 (2008).

[10] D. A. Roberts and R. W. Bybee, Scientific literacy, science literacy, and science education, in Handbook of Research on Science Education, edited by S. K. Abell and N. Lederman (Routledge, 2014), Vol. II, pp. 559-572.

[11] O. Levrini, P. Fantini, B. Pecori, G. Tasquier, and M. Levin, Defining and operationalizing 'appropriation' for science learning, J. Learn. Sci. 24, 93 (2015).

[12] O. Levrini, M. Levin, P. Fantini, and G. Tasquier, Orchestration of classroom discussions that foster appropriation, Sci. Educ. 103, 206 (2019).

[13] R. Duit, H. Gropengießer, and U. Kattmann, Towards science education research that is relevant for improving practice: The model of educational reconstruction, in Developing Standards in Research on Science Education, edited by H. E. Fischer (Taylor \& Francis, London, 2005), pp. 1-9.

[14] N. S. Nasir, A. S. Rosebery, B. Warren, and C. D. Lee, Learning as a cultural process, in The Cambridge 
Handbook of The Learning Sciences, edited by K. Sawyer (Cambridge University Press, Cambridge, England, 2006), pp. 489-504.

[15] A. A. diSessa and B. L. Sherin, What changes in conceptual change?, Int. J. Sci. Educ. 20, 1155 (1998); A. A. diSessa, B. Sherin, and M. Levin, Knowledge analysis: An introduction, in Knowledge and Interaction: A Synthetic Agenda for the Learning Science, edited by A. A. diSessa, M. Levin, and N. J. S. Brown (Taylor \& Francis, New York, NY, 2016), pp. 30-61.

[16] R. Duit, Science education research internationally: Conceptions, research methods, domains of research, Eurasia J. Math. Sci. Technol. Educ. 3, 3 (2007).

[17] R. Duit, M. Komorek, and J. Wilbers, Studies on educational reconstruction of chaos theory, Res. Sci. Educ. 27, 339 (1997).

[18] M. Komorek and R. Duit, The teaching experiment as a powerful method to develop and evaluate teaching and learning sequences in the domain of non-linear systems, Int. J. Sci. Educ. 26, 619 (2004).

[19] E. M. van Dijk and U. Kattmann, A research model for the study of science teachers' PCK and improving teacher education, Teaching Teacher Educ. 23, 885 (2006).

[20] A. Laherto, Informing the development of science exhibitions through educational research, Int. J. Sci. Educ. 3, 121 (2013).

[21] O. Levrini, The substantivalist view of spacetime proposed by Minkowski and its educational implications, Sci. Educ. 11, 601 (2002).

[22] O. Levrini, The role of history and philosophy in research on teaching and learning of relativity, in International Handbook of Research in History, Philosophy and Science Teaching, edited by M. R. Matthews (Springer, Netherlands, 2014), pp. 157-181.

[23] O. Levrini and P. Fantini, Encountering productive forms of complexity in learning modern physics, Sci. \& Educ. 22, 1895 (2013).

[24] A. De Ambrosis and O. Levrini, How physics teachers approach innovation: An empirical study for reconstructing the appropriation path in the case of special relativity, Phys. Rev. ST Phys. Educ. Res. 6, 020107 (2010).

[25] A. A. diSessa, Toward an epistemology of physics, Cognit. Instr. 10, 105 (1993).

[26] J. F. Wagner, Transfer in pieces, Cognit. Instr. 24, 1 (2006).

[27] J.F. Wagner, A transfer-in-pieces consideration of the perception of structure in the transfer of learning, J. Learn. Sci. 19, 443 (2010).

[28] O. Parnafes, What does "fast" mean? Understanding the physical world through computational representations, J. Learn. Sci. 16, 415 (2007).

[29] O. Levrini and A. A. diSessa, How students learn from multiple contexts and definitions: Proper time as a coordination class, Phys. Rev. ST Phys. Educ. Res. 4, 010107 (2008).

[30] C. M. Lewis, Applications of out-of-domain knowledge in students' reasoning about computer program state, Ph.D. thesis, University of California, Berkeley, CA, 2012.

[31] J. P. Smith III, A. A. diSessa, and J. Roschelle, Misconceptions reconceived: A constructivist analysis of knowledge in transition, J. Learn. Sci. 3, 115 (1994).
[32] R. E. Scherr, Modeling student thinking: An example from special relativity, Am. J. Phys. 75, 272 (2007).

[33] G. Tasquier, O. Levrini, and J. Dillon, Exploring students' epistemological knowledge of models and modelling in science: Results from a teaching/learning experience on climate change, Int. J. Sci. Educ. 38, 539 (2016).

[34] M. Stieff, M. Ryu, and J. C. Yip, Speaking across levelsgenerating and addressing levels confusion in discourse, Chem. Educ. Res. Pract. 14, 376 (2013).

[35] [35] G. Erickson and A. Tiberghien, Heat and temperature, in Children's Ideas in Science, edited by R. Driver, E. Guesne, and A. Tiberghien (Open University Press, Milton Keynes-Philadelphia, 1985), pp. 52-84.

[36] S. Kesidou and R. Duit, Students' conceptions of the second law of thermodynamics-an interpretive study, J. Res. Sci. Teach. 30, 85 (1993).

[37] L. Viennot, Experimental facts and ways of reasoning in thermodynamics: Learner's common approach, in Connecting Research in Physics Education with Teacher Education edited by A. Tiberghien, E. L. Jossem, and J. Barojas (An I.C.P.E. Book (C) International Commission on Physics Education, 1997).

[38] U. Besson, Work and energy in the presence of friction: The need for a mesoscopic analysis, Eur. J. Phys. 22, 613 (2001).

[39] M. E. Loverude, C. H. Kautz, and P. R. L. Heron, Student understanding of the first law of thermodynamics: Relating work to the adiabatic compression of an ideal gas, Am. J. Phys. 70, 137 (2002).

[40] D. Meltzer, Investigation of students' reasoning regarding heat, work, and the first law of thermodynamics in an introductory calculus-based general physics course, Am. J. Phys. 72, 1432 (2004).

[41] H. Kautz, P. R. L. Heron, M. E. Loverude, and L. C. McDermott, Student understanding of the ideal gas law, Part I: A macroscopic perspective, Am. J. Phys. 73, 1055 (2005); Student understanding of the ideal gas law, Part II: A microscopic perspective, Am. J. Phys. 73, 1064 (2005).

[42] E. B. Pollock, J. R. Thompson, and D. B. Mountcastle, Student understanding of the physics and mathematics of process variables in pv diagrams, AIP Conf. Proc. 951, 152 (2007).

[43] S. Rozier and L. Viennot, Students' reasoning in thermodynamics, Int. J. Sci. Educ. 13, 159 (1991).

[44] Relating Macroscopic Phenomena to Microscopic Particles, edited by P. Lijnse, P. Licht, W. de Vos, and A. Waarlo(CD-ß Press Utrecht, Holland, 1990).

[45] W. M. Christensen, D. E. Meltzer, and C. A. Ogilvie, Student ideas regarding entropy and the second law of thermodynamics in an introductory physics course, Am. J. Phys. 77, 907 (2009).

[46] M. J. Cochran and P. R. L. Heron, Development and assessment of research-based tutorials on heat engines and the second law of thermodynamics, Am. J. Phys. 74, 734 (2006).

[47] M. E. Loverude, Student understanding of basic probability concepts in an upper-division thermal physics course, AIP Conf. Proc. 1179, 189 (2009).

[48] E. H. Lieb and J. Yngvason, The physics and mathematics of the second law of thermodynamics, Phys. Rep. 310, 1 (1999). 
[49] A. B. Arons, A Guide to Introductory Physics Teaching (Wiley New York, 1990), p. 342.

[50] C. Tarsitani, Dalla meccanica alla termodinamica. Spunti per una riflessione didattica, Internal report (2003) (unpublished).

[51] F. Duprè, Il secondo principio della termodinamica e l'entropia: una proposta di itinerario didattico, in Calore, Energia, Entropia. Le Basi Concettuali della Termodinamica e il Loro Sviluppo Storico, edited by C. Tarsitani and M. Vicentini (Franco Angeli, Milano-Roma, 1991), p. 352.

[52] M. Vicentini Missoni, Dal Calore all'Entropia (La Nuova Italia Scientifica, Roma, 1992).

[53] C. Tarsitani, Looking at the second law of thermodynamics through the eyes of Maxwell's demon, in Thinking Physics for Teaching, edited by C. Bernardini, C. Tarsitani, and M. Vicentini (Springer, Boston, MA, 1995), pp 355-366.

[54] C. Tarsitani and D. Busini, Macroscopic vs microscopic: A problem of history, epistemology, and teaching of physics, in Proceedings of the GIREP-ICPE '95, edited by $\mathrm{M}$. Michelini et al. (FORUM, Udine, 1996), pp. 281-286.

[55] U. Besson, Teaching about thermal phenomena and thermodynamics: The contribution of the history and philosophy of science, in International Handbook of Research in History, Philosophy and Science Teaching, edited by M. R. Matthews (Springer, New York, 2014), pp. 245-283; C. Tarsitani and M. Vicentini, Calore, Energia, Entropia (Franco Angeli, Roma, 1991).

[56] A. Einstein, Time, Space, and Gravitation, Times (London), 28 November 1919 (1919).

[57] O. Levrini, P. Fantini, B. Pecori, and G. Tasquier, Forms of productive complexity as criteria for educational reconstruction: the design of a teaching proposal on thermodynamics, Procedia Soc. Behav. Sci. 116, 1483 (2014).
[58] M. Bakhtin, Discourse in the novel, in The Dialogic Imagination, edited by M. Holquist (University of Texas Press, Austin, 1981), pp. 259-422 [translated by M. Holquist and C. Emerson].

[59] B. Rogoff, Observing sociocultural activity on three planes: Participatory appropriation, guided participation, and apprenticeship, in Sociocultural Studies of Mind, edited by J. V. Wertsch, P. del Rio, and A. Alvarez (Cambridge University Press, Cambridge, England, 1995), pp. 139-164.

[60] N. S. Nasir and V. Hand, From the court to the classroom: Opportunities for engagement, learning, and identity in basketball and classroom mathematics, J. Learn. Sci. 17, 143 (2008).

[61] O. Levrini, M. Levin, and P. Fantini, Personal, deeply affective, and aesthetic engagement with science content: when disciplinary learning becomes a vehicle for identity construction, in Converging Perspectives on Conceptual Change. Mapping an Emerging Paradigm in the Learning Sciences, edited by T. G. Amin and O. Levrini (Routledge London and New York, 2018), pp. 305-312.

[62] A. A. diSessa and J.F. Wagner, What coordination has to say about transfer, in Transfer of Learning from a Modern Multidisciplinary Perspective, edited by $\mathrm{J}$. Mestre (Information Age Publishing Greenwich, CT, 2005), pp. 121-154.

[63] M. Levin, O. Levrini, and J. Greeno, Converging perspectives on conceptual change, in Mapping an Emerging Paradigm in the Learning Sciences, edited by T. G. Amin and O. Levrini (Routledge London and New York, 2018), pp. 313-333.

[64] S. Kapon, A. Laherto, and O. Levrini, Disciplinary authenticity and personal relevance in school science, Sci. Educ. 102, 1077 (2018). 